\title{
Perception without awareness: Further evidence from a Stroop priming task
}

\author{
M. TERESA DAZA and JUAN J. ORTELLS \\ University of Almería, Almería, Spain \\ and \\ ELAINE FOX \\ University of Essex, Essex, England
}

\begin{abstract}
In the present research, we examined the influence of prime-target stimulus onset asynchrony (SOA) on Stroop-priming effects from masked words. Participants indicated the color of a central target, which was preceded by a 33-msec prime word followed either immediately or after a variable delay by a pattern mask. The prime word was incongruent or congruent with the target color on $75 \%$ and $25 \%$ of the trials, respectively. The words followed by an immediate mask produced reliable Stroop interference at SOAs of 300 and $400 \mathrm{msec}$ but not at SOAs of 500 and $700 \mathrm{msec}$. The words followed by a delayed mask produced a reversed (i.e., facilitatory) Stroop effect, which reached significance at an SOA of 400 msec or longer, but never at the shorter 300-msec SOA. Such an differential time course of both types of Stroop priming effects provides further evidence for the existence of qualitative differences between conscious and nonconscious perceptual processes.
\end{abstract}

The question of whether perception can occur without awareness has been the focus of considerable research and discussion for many years (for recent reviews, see Merikle \& Daneman, 1998; Merikle, Smilek, \& Eastwood, 2001). The logic followed by the majority of studies within experimental psychology has been to demonstrate a dissociation between two indexes or measures of perception that are assumed to assess perception with and without awareness, respectively. It has been widely assumed that a prerequisite for a dissociation between measures of conscious and unconscious perception is that the index of conscious perception must provide an exhaustive measure of all relevant conscious experiences and that such a measure actually exhibit null sensitivity (Merikle, 1992; Reingold \& Merikle, 1990). Two general classes of exhaustive measures of conscious awareness have been used: subjective and objective. With subjective measures, awareness is assessed on the basis of the observers' introspective selfreports of their conscious perceptual experiences (e.g., Cheesman \& Merikle, 1986; Forster \& Davis, 1984; Sidis, 1898; see Adams, 1957, for a review of the earliest studies). With objective measures, the absence of relevant con-

\footnotetext{
This research was partly supported by Grant BSO2000-1411-C02-02 from Ministerio de Ciencia y Tecnología, Dirección General de Investigación (Spain), to the second author. The findings of Experiment 2 were presented at the II Congress of the Spanish Society of Experimental Psychology (SEPEX), March, 2000, Barcelona, Spain. Correspondence should be addressed to either M. T. Daza or J. J. Ortells, Departamento de Neurociencia y Ciencias de la Salud, Facultad de Humanidades y Ciencias de la Educación, Universidad de Almería, 04120 Almería, Spain (e-mail: tdaza@ual.es; jortells@ual.es).
}

scious experience is indexed by some behavioral measure that demonstrates an observer's inability to discriminate between alternative stimulus states (see, e.g., Balota, 1983; Fowler, Wolford, Slade, \& Tassinary, 1981; Greenwald, Draine, \& Abrams, 1996; Kunst-Wilson \& Zajonc, 1980; Marcel, 1983a, 1983b). Considerable discussion has taken place regarding whether subjective or objective measures provide the more accurate method for demonstrating perception without awareness (e.g., Eriksen, 1960; Holender, 1986; Reingold \& Merikle, 1990). In either case, a major weakness of traditional approaches using the dissociation paradigm is that the conclusiveness of findings presumed to provide evidence for unconscious perception depends entirely on the adequacy of the measures used to define consciousness. As noted by Merikle and Joordens (1997b), the attempt to merely prove the existence (or nonexistence) of unconscious perception does not appear to be a particularly useful strategy. This is because it is impossible to demonstrate convincingly that a null sensitivity equates with the absence of conscious perception of the relevant information, regardless of whether a subjective or an objective measure of awareness is used.

As an alternative to establishing dissociations between measures, a more interesting question that can be addressed is how unconscious perception differs from conscious perception. In other words, perception with and without awareness must be compared in order to determine whether a stimulus can have qualitatively different effects on cognitive and affective reactions depending on whether it is either consciously or unconsciously perceived. As noted by Merikle et al. (2001), the logic underlying this alternative approach assumes that the information consciously per- 
ceived enables individuals to act intentionally and to produce effects in the world, whereas information perceived without awareness leads to more automatic reactions that cannot be controlled by individuals (e.g., Marcel, 1988; Searle, 1992). A good example of how conscious and unconscious perceptual processes differ comes from the $e x$ clusion task used by Debner and Jacoby (1994; for other interesting qualitative differences in the consequences of perception with and without awareness, see also Groeger, 1984, 1988; Kunst-Wilson \& Zajonc, 1980; Marcel, 1980; Murphy \& Zajonc, 1993). On each trial, a single word (e.g., table) was presented for either a short (i.e., 50$\mathrm{msec}$ ) or a somewhat longer (i.e., 150-msec) duration and was followed by a mask. Immediately following the mask, the first three letters of the word were presented again (e.g., tab__, and the participants were required to complete the word stem with any word that came to mind $e x$ cept the word that had just been presented (e.g., they could complete the word stem with taboo, but not table). Debner and Jacoby found that participants were able to follow these exclusion instructions only when the word was presented for the longer 150-msec duration. But for the short 50-msec duration, they used the preceding words to complete the word stems on a proportion of trials that was significantly above chance. This finding suggests that the words were unconsciously perceived in the $50-\mathrm{msec}$ condition.

It is interesting to note that the exclusion procedure provides particularly compelling evidence for unconscious perception, since conscious and unconscious influences are placed "in opposition." On the contrary, most of the traditional approaches have used facilitation paradigms, whereby effects on unconscious perception of a stimulus produce the same pattern (i.e., a facilitation in performance) as does conscious perception. According to Debner and Jacoby (1994), because both types of processes can contribute to performance in a similar vein (i.e., facilitating), it is difficult to determine whether the supposedly unconscious influences might partly or completely be attributed to residual conscious perception. In contrast, in studies using procedures such as the exclusion task, evidence of unconscious perception cannot be explained as truly resulting from conscious perception, since the latter would produce an opposite pattern of results.

A procedure fairly similar to Debner and Jacoby's (1994) exclusion task has also been used by Merikle and colleagues in an elegant series of Stroop-priming studies showing that individuals can use predictive strategies based on stimulus redundancy only when the predictive stimuli are consciously perceived (e.g., Cheesman \& Merikle, 1986; Merikle \& Cheesman, 1987; Merikle \& Joordens, 1997a, 1997b; Merikle, Joordens, \& Stolz, 1995). Their experiments were based on a variant of the Stroop (1935) color-word interference task, in which two color words (RED or GREEN) were used to prime responses to a probe target (e.g., a color patch or a series of ampersands that was also red or green). For example, Merikle and Joordens (1997b, Experiment 1A) presented a single central prime word (RED or GREEN in gray color) for $33 \mathrm{msec}$, which was followed either immediately or after a delay of $134 \mathrm{msec}$ (depending on the group of participants) by a pattern mask (seven ampersands in gray color), thus resulting in a prime-mask stimulus onset asynchrony (SOA) of either $33 \mathrm{msec}^{1}$ or $167 \mathrm{msec}$, respectively. The masked prime word was always followed by a central target, which consisted of seven ampersands displayed, until response, in either red or green, with participants being required to make a buttonpress response to indicate the target color as quickly as possible. For both groups of participants, the prime-target SOA remained fixed at $300 \mathrm{msec}$. The prime and the target were incongruent (RED-green) on $75 \%$ of the trials, whereas on the remaining $25 \%$ of the trials, the prime and the target were congruent (RED-red). Merikle and Joordens (1997b) found a significant crossover interaction between masking condition and prime-target congruency: With a delayed mask (i.e., a prime-mask SOA of $167 \mathrm{msec}$ ), the reaction times (RTs) were faster on incongruent than on congruent trials. Such a reversed (i.e., facilitatory) Stroop effect suggests that participants consciously identified the prime word followed by a delayed mask and then used the predictive information provided by the word to anticipate the forthcoming target color (see also Logan, Zbrodoff, \& Williamson, 1984). In contrast, with an immediate mask (i.e., a prime-mask SOA of $33 \mathrm{msec}$ ), a typical Stroop interference effect (slower RTs on incongruent than on congruent trials) emerged, suggesting that participants experienced no awareness of the primes when they were presented for $33 \mathrm{msec}$ and were immediately followed by a mask. This crossover in performance across masking conditions (see also Merikle et al., 1995; Merikle \& Joordens, 1997a) is consistent with the view that perception with awareness and perception without awareness can produce qualitatively different behavioral consequences.

Note, however, that the Stroop priming effects reported by Merikle and Joordens (1997b) were of a relatively small size. More importantly, to the extent that the reversed Stroop effect under the delayed masking condition reflected the contribution of strategic processes, such a result could be viewed as an unusual finding given the primetarget SOA (300 msec) that was used by these authors (see also Merikle et al., 1995). To illustrate, there is ample evidence from priming studies that the relative contribution to performance of controlled or strategy-based influences is usually apparent at about 400-500 msec (e.g., De Groot, 1984; Fuentes \& Tudela, 1992; Neely, 1977; Ortells, Abad, Noguera, \& Lupiáñez, 2001; Posner \& Snyder, 1975; Shenaut $\&$ Ober, 1996). Thus, it seems unlikely that an SOA of $300 \mathrm{msec}$ would give participants sufficient time to use the prime word in a strategic manner to anticipate the target color. ${ }^{2}$

The aim of the present research was to explore the generality of results reported by Merikle and Joordens (1997b; see also Merikle et al., 1995), since there are few independent replications of qualitative differences attributed to perception with and without awareness. In other words, 
we investigated whether the qualitatively different Stroop priming effects that were observed as a function of the prime-mask SOA constitute a generally robust finding, or whether they occur only under a limited set of experimental conditions (e.g., a particular prime-target SOA interval, a particular type of instructions). To this end, we conducted a series of experiments using Merikle and Joorden's (1997b) task, in which we manipulated the instructions given to participants, as well as the SOA between the prime word and the target color (including SOA intervals longer than $300 \mathrm{msec}$ ).

\section{EXPERIMENT 1}

In the first experiment, we used exactly the same procedure as that of Merikle and Joordens (1997b, Experiment $1 \mathrm{~A})$. The participants were required to indicate the color (red or green) of a central target (a series of ampersands) that was preceded $300 \mathrm{msec}$ before by a central prime word (RED or GREEN) that was presented for $33 \mathrm{msec}$. An incongruent prime-target pair (e.g., RED-green) was always three times as probable (75\%) as a congruent prime-target pair (e.g., RED-red). For two groups of participants, the prime word was immediately followed by a 267-msec masking pattern (immediate-masking conditions). For two other groups, the prime was followed by a 134-msec blank screen and then by a 133 -msec pattern mask (delayed-masking conditions).

Although Merikle and Joordens (1997b) did not mention what kind of instructions were given to their participants, it could be the case that obtaining a reliable reversed Stroop at a prime-target SOA of $300 \mathrm{msec}$ depends critically on explicitly instructing participants to use the prime word to anticipate the target color. To address this possibility, two kinds of instructions were used. Half of the participants in each masking condition were told that the main goal of the experiment was to investigate how well they could learn to use a predictive strategy to improve their performance. Accordingly, the participants were explicitly informed that given a prime word (e.g., RED), they should expect that the color target would be the color not named by the word, since incongruent prime-target pairings were much more frequent than congruent ones. The other half of participants in each masking condition were also informed about the differential proportion of incongruent $(75 \%)$ and congruent $(25 \%)$ trials. However, they were told that the main goal of the experiment was to investigate how fast they could identify the color (red or green) of a series of ampersands (the target).

If the kind of instructions given to the participants in this task is critical, we should observe a reversed Stroop effect only when the participants are actively encouraged to capitalize on the predictive information provided by the prime word.

\section{Method}

Participants. Eighty-eight (22 participants for each group) undergraduate students at the University of Almería participated in a single experimental session for course credit. All had normal or corrected-to-normal vision and were $19-25$ years old $($ mean $=22$ ).

Apparatus and Stimuli. The stimuli were displayed on a VGA color monitor controlled by Micro Experimental Laboratory (MEL) software (Schneider, 1988) implemented on an IBM/PC-compatible computer. Responses were collected on a computer keyboard; response accuracy and latency to the nearest millisecond were measured by the MEL software. All stimuli were displayed in uppercase characters against a black background, and they were centered both horizontally and vertically at a viewing distance of approximately $65 \mathrm{~cm}$. Two color words (RED or GREEN) were used as prime stimuli, with each letter subtending about $0.35^{\circ}$ horizontally and $0.52^{\circ}$ vertically. A string of seven ampersands (\&\&\&\&\&\&\&) subtending about $2.46^{\circ}$ horizontally and $0.52^{\circ}$ vertically was used as both the pattern mask and the target, with the only difference being the color of the ampersands (gray for the mask, and either red or green for the target). The participants indicated the color of the target by pressing either the "M" or the " $\mathrm{C}$ " key on the computer keyboard. Mapping of responses and correct key ("M" or "C") were counterbalanced across subjects.

Procedure. The participants were tested individually in a soundattenuated, dimly lit room. General task instructions were displayed on the monitor and were also relayed verbally. The timing of the specific stimulus events on each trial for the immediate masking (prime-mask SOA of $33 \mathrm{msec}$ ) groups was as follows: (1) The fixation display (*) was presented for $500 \mathrm{msec}$; (2) the prime word (RED or GREEN) was displayed in dark-gray letters and was presented for $33 \mathrm{msec}$; (3) the mask (i.e., \&\&\&\&\&\&\&) was displayed in darkgray and was presented for $267 \mathrm{msec}$; and (4) the target (i.e., $\& \& \& \& \& \& \&)$ was displayed in either red or green and was presented until the participant's response. The prime-target pairings were incongruent (i.e., RED-green) on $75 \%$ of the trials and congruent (i.e., RED-red) on the remaining $25 \%$ of the trials. The participants were told that their task on each trial was to indicate the color of the ampersands as quickly and accurately as possible after the color changed from gray to either red or green. The computer emitted a 500-msec beep if the participants made an error. Following the participant's response a new trial began.

The sequence of events on each trial for the delayed masking (prime-mask SOA of $167 \mathrm{msec}$ ) groups was the same as that under the immediate masking conditions, with the only difference being that the presentation of the 33-msec prime word was now followed by a blank screen for $134 \mathrm{msec}$ and was then followed by the ampersand mask for $133 \mathrm{msec}$.

The participants in each group took part in a single session (lasting about $35 \mathrm{~min}$ ) consisting of one block of 48 practice trials followed by six experimental blocks of 48 trials. ${ }^{3}$ From the 48 trials of each block, 36 were incongruent $(75 \%)$ and 12 were congruent $(25 \%)$. Within each of these two trial sets, the target was displayed either in red or in green on the same number of trials. The participants initiated each block of trials by pressing the space bar on the computer keyboard. Once a block of trials was initiated, it ran to completion. Thus, the participants could rest only between blocks of trials.

\section{Results and Discussion}

Mean RTs and error rates were entered into two $2 \times 2 \times 2$ analyses of variance (ANOVAs), with instructions and masking type (immediate vs. delayed mask) as betweensubjects factors and prime-target congruency (incongruent vs. congruent) as a within-subjects factor. ${ }^{4}$

No reliable effects were found in the analysis of error percentages. In the analysis of RTs, the main effect of prime-target congruency was significant $[F(1,84)=8.9$, $\left.M S_{\mathrm{e}}=311, p<.003\right]$, so that RTs were reliably slower for 
incongruent (466 msec) than for congruent $(458 \mathrm{msec})$ trials (i.e., a typical Stroop interference effect). The main effect of instructions was not significant $[F(1,84)=1.7$, $p>.20]$, and interestingly, that factor did not interact with any other variable. Although the prime-target congruency $\times$ masking type interaction did not reach statistical significance $[F(1,84)=2.31, p<.13]$, we conducted further ANOVAs on each masking condition in order to explore whether our Stroop priming pattern was similar to that reported by Merikle and Joordens (1997b). The results of these analyses showed a significant Stroop interference of $-12 \mathrm{msec}$ under the immediate masking condition $\left[F(1,42)=16.8, M S_{\mathrm{e}}=188, p<.0002\right]$. Such a finding successfully replicates that reported by Merikle and Joordens (1997b, Experiment 1A) in that condition, thus suggesting that stimulus information of which we are not subjectively aware can, however, be processed. Nevertheless, unlike in the Merikle and Joordens' (1997b) study, no significant reversed Stroop effect was found with a delayed mask, regardless of whether our participants were actively encouraged to rely on the predictive information provided by the word to optimize their performance (see Table 1). Rather, a nonsignificant $(F<1)$ interference pattern of $-4 \mathrm{msec}$ was obtained.

It could be argued that our participants did not consciously perceive the prime words under the delayed masking condition, thus explaining the failure to replicate the findings by Merikle and Joordens (1997b). If this was the case, however, a significant Stroop interference should have been observed, as was the case with the immediate mask. Additionally, whereas the participants in the immediate masking groups reported a complete absence of conscious perceptual experiences of the prime word, all the participants in the delayed masking groups acknowledged that they had consciously perceived the prime word on most trials. It appears, then, that even though the words followed by a delayed mask were consciously identified, our participants were unable to efficiently use the prime word to anticipate the target color. Moreover, the fact that we observed a similar data pattern irrespective of the kind of instruction given to the participants (note that the instructions did not interact with any other variable) indicates that obtaining a reversed Stroop from a consciously processed word in this task does not critically hinge on explicitly instructing participants to use predictive strategies to guide their performance.

Table 1

Mean Reaction Times (in Milliseconds) and Percent Error as a Function of Instructions, Prime-Target Congruency, and Masking Condition in Experiment 1

\begin{tabular}{|c|c|c|c|c|c|}
\hline \multirow[b]{3}{*}{ Instructions } & \multirow{3}{*}{$\begin{array}{c}\text { Prime-Target } \\
\text { Congruency }\end{array}$} & \multicolumn{4}{|c|}{ Masking Condition } \\
\hline & & \multicolumn{2}{|c|}{ Immediate } & \multicolumn{2}{|c|}{ Delayed } \\
\hline & & RTs & $\mathrm{PE}$ & RTs & PE \\
\hline \multirow[t]{2}{*}{ Nonstrategic } & Incongruent & 451 & .03 & 460 & .03 \\
\hline & Congruent & 441 & .03 & 457 & .03 \\
\hline \multirow[t]{2}{*}{ Strategic } & Incongruent & 474 & .03 & 478 & .04 \\
\hline & Congruent & 461 & .03 & 473 & .05 \\
\hline
\end{tabular}

The reasons for the discrepancy between our results and those reported by Merikle and Joordens (1997b) with a delayed mask remain unclear. However, as previously suggested (see also note 2) obtaining a reliable strategydependent effect (e.g., reversed Stroop) could in some contexts require the use of longer time intervals than those used by Merikle and Joordens (1997b; see also Merikle et al., 1995). To address this possibility, we conducted another experiment, in which different prime-target SOA intervals (including SOAs longer than $300 \mathrm{msec}$ ) were used.

\section{EXPERIMENT 2}

Experiment 2 was procedurally similar to Experiment 1, with just three exceptions: (1) The presence of either an immediate or a delayed mask was manipulated within subjects (across different blocks), instead of between subjects, in order to maximize the probability (i.e., by decreasing error variance) of obtaining a significant interaction between prime-target congruency and masking type; (2) all the participants received identical instructions, which encouraged them to use the prime word in a strategic manner to anticipate the color of the forthcoming target; and (3) four different prime-target SOA intervals $(300,400,500$, and $700 \mathrm{msec}$ ) were used (varied between subjects). On the basis of our results in Experiment 1 , we expected that a consciously processed prime word (i.e., followed by a delayed mask) should produce a significant reversed Stroop effect at SOA intervals longer than $300 \mathrm{msec}$, but not at the 300-msec SOA.

\section{Method}

Participants. Ninety-six (24 for each of the four experimental groups) undergraduate students at the University of Almería participated in the experiment. All had normal or corrected-to-normal vision, and were 19-25 years old (mean $=22$ ).

Stimuli and Procedure. These were similar to those of Experiment 1 , except that (1) in the present experiment the presence of either an immediate or a delayed mask was manipulated within subjects (across different trial blocks), and (2) different prime-target SOA intervals $(300,400,500$, or $700 \mathrm{msec})$ were used across different groups of participants. For the immediate masking condition, the prime word was presented for $33 \mathrm{msec}$ and was immediately followed by a pattern mask of a variable duration (depending on the group of participants) of 267, 367, 467, or $667 \mathrm{msec}$. This resulted in prime-target SOAs of 300, 400, 500, and $700 \mathrm{msec}$, respectively. For the delayed masking condition, the prime word (which was also presented for $33 \mathrm{msec}$ ) was followed by a blank screen of a variable duration of 134, 234, 334, or $534 \mathrm{msec}$ (depending on the group of participants) and then by a 133 -msec pattern mask (this resulted in prime-target SOAs of 300, 400, 500, and $700 \mathrm{msec}$, respectively). ${ }^{5}$

Each participant took part in a single session (lasting about $25 \mathrm{~min}$ ) consisting of two blocks of 168 trials (24 practice trials followed by 144 experimental trials), one block for each masking condition (i.e., immediate and delayed). The order of the blocks was counter balanced across subjects. From the 144 experimental trials of each block, 108 were incongruent (75\%), and 36 were congruent $(25 \%)$. Within each of these two trial sets, the target was displayed either in red or in green on the same number of trials. The participants initiated each trial block by pressing the space bar on the computer keyboard. Once a block of trials was initiated, it ran to completion, so that the participants could rest only between blocks. 


\section{Results and Discussion}

Mean RTs and error percentages were entered into two $2 \times 2 \times 4$ ANOVAs, with masking condition (immediate vs. delayed) and prime-target congruency (incongruent vs. congruent) as within-subjects factors and prime-target SOA $(300,400,500$, and $700 \mathrm{msec})$ as a between-subjects factor. In the analysis of RTs, the main effect of masking condition was significant $\left[F(1,92)=24.1, M S_{\mathrm{e}}=9,948.4\right.$, $p<.0001]$, as was the interaction between this variable and prime-target SOA $\left[F(3,92)=3.41, M S_{\mathrm{e}}=9,948.4, p<\right.$ .02]. RTs were faster following an immediate than following a delayed mask at SOAs of 300,400, and $500 \mathrm{msec}$ (at the 700-msec SOA, this difference did not reach significance). The main effect of prime-target congruency was also significant $\left[F(1,92)=10.7, M S_{\mathrm{e}}=819, p<.0015\right]$, as was the interaction between this factor and masking condition $\left[F(1,92)=37.1, M S_{\mathrm{e}}=612, p<.0001\right]$. The analysis of this interaction revealed a reliable Stroop interference of $-6 \mathrm{msec}$ with an immediate mask $[F(1,92)=$ $4.7, M S_{\mathrm{e}}=349.4, p<.03$ ] and a significant facilitatory (i.e., reversed Stroop) effect of $+25 \mathrm{msec}$ with the delayed $\operatorname{mask}\left[F(1,92)=27.6, M S_{\mathrm{e}}=1,081.7, p<.0001\right]$. Even though the three-way interaction between SOA, primetarget congruency, and masking type did not reach significance $[F(1,92)=1.08, p<.36]$, we conducted a series of further ANOVAs on each SOA condition to explore whether the Stroop priming effects following each masking condition showed a similar pattern across SOA intervals. The results of these analyses are summarized in Table 2 .

When the prime word was immediately masked, at the briefest prime-target SOA of $300 \mathrm{msec}$, we obtained a significant Stroop interference of $-13 \mathrm{msec}[F(1,23)=5.13$, $\left.M S_{\mathrm{e}}=395, p<.03\right]$, replicating the results of Experiment 1 (see also Merikle \& Joordens, 1997b, Experiment 1A). Although such an interference effect was also significant at the 400-msec SOA $[-10 \mathrm{msec} ; F(1,23)=$ $\left.10.35, M S_{\mathrm{e}}=115.4, p<.004\right]$, this effect disappeared at the longer SOA intervals of 500 and $700 \mathrm{msec}$ (see Table 2), suggesting that priming effects from unconscious perception in this kind of task could have a relatively fast decay over time.

On the other hand, an opposite facilitation (i.e., reversed Stroop) effect was found when the prime word was followed by a delayed mask. Although such an effect was of a greater size than that reported by Merikle and Joordens (1997b, Figure 1, p. 224), it reached significance with an SOA interval of $400 \mathrm{msec}[+36 \mathrm{msec} ; F(1,23)=$ $\left.13.01, M S_{\mathrm{e}}=1,167.4, p<.001\right]$ or longer [500 $\mathrm{msec}=$ $+30 \mathrm{msec} ; F(1,23)=8.15, M S_{\mathrm{e}}=1,344.7, p<.009$; $700 \mathrm{msec}=+26 \mathrm{msec} ; F(1,23)=6.04, M S_{\mathrm{e}}=1,340.6$, $p<.02]$, but not at the briefest $300-\mathrm{msec}$ SOA [ $+8 \mathrm{msec}$; $F(1,23)=1.6, p>.22]$. The absence of a reversed Stroop at the prime-target SOA of $300 \mathrm{msec}$ in this and the previous experiment suggests that such an SOA interval does not constitute enough time, at least in our research, to allow most of our participants to efficiently use the predictive information provided by the word to anticipate the target color. 6
The results of error percentage mirrored the RT data. There was a significant main effect of masking condition $\left[F(1,92)=34.5, M S_{\mathrm{e}}=0.0052, p<.0001\right]$, so that there was a higher error rate with a delayed (.077) than with an immediate mask (.034). The main effect for prime-target congruency was also significant $\left[F(1,92)=24.5, M S_{\mathrm{e}}=\right.$ $0.0033, p<.0001]$, as well as the interaction of this factor with masking type $\left[F(1,92)=20.25, M S_{\mathrm{e}}=0.0034\right.$, $p<.0001$ ], which revealed a significant facilitatory (i.e., reversed Stroop) effect in the delayed masking condition $\left[F(1,92)=24.04, M S_{\mathrm{e}}=0.0062, p<.0001\right]$.

In contrast to Experiment 1, in the present experiment, we replicated the crossover interaction between primetarget congruency and masking condition that was reported by Merikle and Joordens (1997b). Nevertheless, it is interesting to note that this interaction was observed only in one of the prime-target SOA conditions that were tested (see Table 2) - namely, at the 400-msec SOA. It appears, then, that although qualitatively different Stroop priming effects from masked words can be observed as a function of the prime-mask SOA, as reported by Merikle and Joordens (1997b), such a data pattern occurs only under a limited set of experimental conditions (e.g., a particular prime- target SOA interval).

The results of the Experiment 2 suggest a differential time course of the Stroop priming effects from consciously versus unconsciously processed words. However, stronger evidence in support of such a conclusion is clearly needed, since the interaction of prime-target congruency, masking type, and SOA failed to reach statistical significance. To this end, we conducted Experiment 3.

\section{EXPERIMENT 3}

We used the same procedure as in Experiment 2, but this time, we used only two SOA intervals (300 and $700 \mathrm{msec}$ ), and both SOAs varied randomly throughout the experi-

Table 2

Mean Reaction Times (in Milliseconds) and Percent Error as a Function of Prime-Target SOA, Prime-Target Congruency, and Masking Condition for Experiments 2 and 3

\begin{tabular}{|c|c|c|c|c|c|}
\hline \multirow[b]{3}{*}{ SOA } & \multirow{3}{*}{$\begin{array}{c}\text { Prime-Target } \\
\text { Congruency }\end{array}$} & \multicolumn{4}{|c|}{ Masking Condition } \\
\hline & & \multicolumn{2}{|c|}{ Immediate } & \multicolumn{2}{|c|}{ Delayed } \\
\hline & & RTs & $\mathrm{PE}$ & RTs & $\mathrm{PE}$ \\
\hline \multicolumn{6}{|c|}{ Experiment 2} \\
\hline \multirow[t]{2}{*}{$300 \mathrm{msec}$} & Incongruent & 453 & .04 & 487 & .06 \\
\hline & Congruent & 440 & .03 & 495 & .10 \\
\hline \multirow[t]{2}{*}{$400 \mathrm{msec}$} & Incongruent & 438 & .02 & 510 & .04 \\
\hline & Congruent & 428 & .02 & 546 & .08 \\
\hline \multirow[t]{2}{*}{$500 \mathrm{msec}$} & Incongruent & 508 & .03 & 549 & .05 \\
\hline & Congruent & 508 & .04 & 579 & .11 \\
\hline \multirow[t]{2}{*}{$700 \mathrm{msec}$} & Incongruent & 462 & .02 & 452 & .03 \\
\hline & Congruent & 461 & .03 & 478 & .10 \\
\hline \multicolumn{6}{|c|}{ Experiment 3} \\
\hline \multirow[t]{2}{*}{$300 \mathrm{msec}$} & Incongruent & 484 & .03 & 526 & .06 \\
\hline & Congruent & 469 & .02 & 523 & .12 \\
\hline \multirow[t]{2}{*}{$700 \mathrm{msec}$} & Incongruent & 449 & .04 & 454 & .06 \\
\hline & Congruent & 449 & .06 & 505 & .15 \\
\hline
\end{tabular}


ment. By manipulating the prime-target SOA in a withinsubjects (random) instead of a between-subjects design (as in Experiment 2), we attempted to reduce error variance in order to increase the likelihood of obtaining a significant three-way interaction of prime-target congruency, masking type, and prime-target SOA. Of more importance, with the two SOAs varying randomly from trial to trial, a differential time course for both types of Stroop priming effects could not be attributed to strategy shifts across SOA conditions (as might have been the case in Experiment 2, in which the SOA was manipulated between subjects).

\section{Method}

Participants. Thirty undergraduate students at the University of Almería participated in this experiment. All had normal or correctedto-normal vision and were $19-26$ years old $($ mean $=22.5$ ).

Stimuli and Procedure. These were the same as those in Experiment 2 , with the only difference being that only two SOA levels were used ( 300 vs. $700 \mathrm{msec}$ ), and this factor was manipulated in a within-subjects (random) design.

\section{Results and Discussion}

Mean RTs and error percentages were entered into two $2 \times 2 \times 2$ ANOVAs, with masking condition (immediate vs. delayed), prime-target congruency (incongruent vs. congruent), and prime-target SOA (300 vs. $700 \mathrm{msec}$ ) as within-subjects factors. In the analysis of RTs, the main effects of masking condition $\left[F(1,29)=8.21, M S_{\mathrm{e}}=\right.$ $11,138, p<.007]$ and SOA $\left[F(1,29)=26.5, M S_{\mathrm{e}}=\right.$ $2,951, p<.0001]$ were significant; RTs were faster following an immediate $(463 \mathrm{msec})$ than following a delayed $(502 \mathrm{msec})$ mask and faster at the $700-(465 \mathrm{msec})$ than at the $300-\mathrm{msec}(501 \mathrm{msec})$ SOA. The masking condition $\times$ prime-target congruency interaction was again significant $\left[F(1,29)=8.31, M S_{\mathrm{e}}=1,788, p<.007\right]$, which revealed a reliable facilitation effect with the delayed mask $\left[F(1,29)=7.13, M S_{\mathrm{e}}=2,411, p<.01\right]$ and a nonsignificant Stroop interference with the immediate mask. Of more interest, however, was a significant three-way interaction of masking condition, prime-target congruency, and primetarget SOA $\left[F(1,29)=4.96, M S_{\mathrm{e}}=1,102, p<.034\right]$. Further analyses of this interaction revealed that the prime words followed by an immediate mask produced a reliable Stroop interference of $-15 \mathrm{msec}$ at the shorter 300-msec SOA $\left[F(1,29)=8.05, M S_{\mathrm{e}}=447, p<.008\right]$, which declined to 0 at the SOA of $700 \mathrm{msec}$ (see Table 2). The words followed by a delayed mask also produced a different Stroop priming pattern across SOAs. As in Experiment 2, a significant reversed Stroop effect of $+51 \mathrm{msec}$ was found at $700 \mathrm{msec}\left[F(1,29)=16.7, M S_{\mathrm{e}}=2,330, p<.0003\right]$ but not at the briefest $300-\mathrm{msec}$ SOA $(-3 \mathrm{msec} ; F<1)$. Accordingly, the results of Experiment 3 replicate the main findings of the previous two experiments and provide stronger evidence that the qualitatively different Stroop priming effects observed under immediate versus delayed masking conditions, respectively, show different time courses.

The results for error percentage mirrored those for the RT data. There were main effects of masking condition
$\left[F(1,29)=34.2, M S_{\mathrm{e}}=0.0069, p<.0001\right]$ and primetarget congruency $\left[F(1,29)=20.04, M S_{\mathrm{e}}=0.0061, p<\right.$ $.0001]$. There was also a significant interaction between both factors $\left[F(1,29)=13.9, M S_{\mathrm{e}}=0.0052, p<.0008\right]$, which revealed a significant reversed Stroop effect under the delayed masking condition $\left[F(1,29)=19.4, M S_{\mathrm{e}}=\right.$ $0.0098, p<.0001]$.

\section{GENERAL DISCUSSION}

In the past decade, an increasing number of investigations have attempted not only to prove the existence of unconscious perceptual processes, but also to demonstrate that behavioral consequences of unconscious perception can be qualitatively different from those of conscious perception. A good example is provided by a series of Stroop priming studies conducted by Merikle and colleagues, which demonstrated that predicting the color of forthcoming targets occurred only when the predictive stimuli were consciously perceived (e.g., Cheesman \& Merikle, 1986; Merikle \& Cheesman, 1987; Merikle \& Joordens, 1997a, 1997b; Merikle et al., 1995).

In the present research, we used the two-color variant of the Stroop task developed by Merikle and Joordens (1997b, Experiment 1A). In this task, participants are required to identify the color (red or green) of a central target (a series of ampersands) that was preceded by a central prime word (RED or GREEN) presented for $33 \mathrm{msec}$, which was incongruent (e.g., RED-green) with the target color on $75 \%$ of the trials and congruent on the remaining $25 \%$. As in Merikle and Joordens' (1997b) study, the likelihood that the prime words were perceived with or without awareness was controlled by varying the stimulus quality, so that the prime word was followed by a mask appearing either immediately (i.e., a prime-mask SOA of $33 \mathrm{msec}$ ) or after a variable delay (depending on the experiment) following word offset. There were two main findings in the present experiments. First, as previously reported by Merikle and Joordens (1997b; see also Merikle et al., 1995), we found that presenting a brief word under immediate versus delayed masking conditions determined whether the word was unconsciously or consciously perceived, since opposite Stroop priming effects (i.e., interference versus facilitationreversed Stroop) were obtained for each masking type. However, such a "crossover" interaction between primetarget congruency and masking type was reliable only at a prime-target SOA of $400 \mathrm{msec}$, but not at either shorter (i.e., $300 \mathrm{msec}$ ) or longer (i.e., 500- and 700-msec) SOA intervals. Accordingly, we successfully replicated the qualitatively different Stroop priming effects that were observed by Merikle and Joordens (1997b) as a function of the masking type (immediate vs. delayed), albeit at a slightly longer SOA interval $(400 \mathrm{msec})$. Our results suggest that qualitative differences in performance can occur, but only at a particular prime-target SOA interval.

A second finding of the present research was that each kind of Stroop priming effect showed a different time 
course. This pattern provides further evidence that perception with awareness and perception without awareness can produce qualitatively different behavioral consequences.

When the stimulus quality of the prime word was poor because of the presence of an immediate mask that followed word offset, the participants in each of our experiments consistently reported a complete absence of conscious awareness of the word's identity. However, the prime word was processed under those circumstances, as revealed by the reliable Stroop interference that was consistently found at the prime-target SOAs of $300 \mathrm{msec}$ in Experiments 1-3. Note also that the size of this interference effect in all of our experiments was very similar to that found by Merikle and Joordens (1997b), who used an identical SOA interval. Interestingly, we also observed that although the Stroop interference was still significant at a prime-target SOA of $400 \mathrm{msec}$ (Experiment 2), it completely disappeared at the longer SOA intervals of $500 \mathrm{msec}$ (Experiment 2) and $700 \mathrm{msec}$ (Experiments 2 and 3), indicating a relatively fast decay over time. To the extent that obtaining a reliable Stroop interference in this kind of task is considered to be a relevant source of evidence for the existence of unconscious perception, our results suggest that future research should take into account the prime-target SOA, since this factor might be a critical determinant of the emergence of Stroop interference from stimuli that are unconsciously perceived.

Regarding the prime words that were followed by a delayed mask, a very different Stroop priming pattern was observed. First, the participants in all of our experiments indicated by self-report that they were aware of the word's identity on most (or many) of these trials. Second, and more important, an opposite facilitation (i.e., reversed Stroop interference) effect was found under the delayed masking condition. However, this effect reached significance at a prime-target SOA of $400 \mathrm{msec}$ or longer (Experiments 2 and 3). At the shortest SOA interval of $300 \mathrm{msec}$ (Experiments $1-3$ ), we consistently failed to find a reliable reversed Stroop effect (see Tables 1 and 2), even when the participants were explicitly encouraged to use the predictive information provided by the word to optimize their performance. On the basis of the literature suggesting that controlled (strategic) processes build up much more slowly (and are often more sustained) than automatic processes (e.g., Neely, 1977; Ortells et al., 2001; Posner \& Snyder, 1975; Shenaut \& Ober, 1996; Shiffrin \& Schneider, 1977), it could be argued that a prime-target SOA of $300 \mathrm{msec}$ would not allow enough time to implement strategic processes (see note 5). However, as pointed out elsewhere (see note 2), it is possible that with a delayed mask, strategic influences might operate at short SOA intervals, but are overridden by an equally strong automatic influence. Such an alternative interpretation could account for the lack of a reliable Stroop priming effect at the 300-msec SOA. Irrespective of whether the reversed Stroop effect in this task reflects the contribution of strategic (controlled) processes, or a combination of both strategic and automatic influences, the present results clearly indicate that consciously perceiving a stimulus constitutes a necessary, though not a sufficient condition, for that stimulus to guide intentional actions. In other words, the fact that a consciously processed prime word gives rise to a reliable priming effect (i.e., reversed Stroop) at some SOA intervals $(400,500$, and $700 \mathrm{msec})$ but not at others $(300 \mathrm{msec})$ suggests that prime awareness is correlated with, but does not directly cause, such a behavioral effect. Thus, the more direct causal link would presumably be between processing strategies and qualitative differences in performance. ${ }^{7}$

How can we explain the fact that Merikle and Joordens (1997b) found a significant reversed Stroop with a delayed mask at a short SOA of $300 \mathrm{msec}$ ? The reasons for the discrepancy between their results and those obtained in our experiments remain unclear. However, an inspection of Figure 1 in their paper (p. 224) suggests that the overall RTs in their study were faster (e.g., lower than $400 \mathrm{msec}$ ) than those obtained in the present experiments (see our Tables 1 and 2). Whereas all of our participants had no prior experience with this kind of task, it could be the case that some (or many) of the subjects in Merikle and Joordens' (1997b) study had previously participated in other similar studies. If this is the case, and on the basis of prior evidence showing that the time necessary to implement strategic processes can be shortened by practice (e.g., Logan \& Zbrodoff, 1982; see also Logan, 1985), it is possible that in Merikle and Joordens' (1997b) study, a seemingly "short" SOA of 300 msec could still represent enough time for the development of strategic effects for a great proportion of their participants.

In either case, the overall pattern in the present research replicates and extends the results of Merikle and Joordens (1997b), in showing that behavioral consequences of perceiving a stimulus with or without phenomenologicalawareness are qualitatively different not only by the sign (i.e., interference vs. facilitation) of the corresponding Stroop priming effect, but also by the time course of each priming effect. An "unconsciously" perceived word resulted in interference effects that were reliable at short SOA intervals but also showed a relatively fast dissipation over time. In contrast, a "consciously" processed word produced an opposite facilitation effect (i.e., reversed Stroop) that was significant at prime-target SOAs longer than those producing reliable interference effects. Whether a similar differential time course of effects stemming from conscious and unconscious perception will be observed in other kinds of dissociative priming procedures remains an interesting matter for future research.

\section{REFERENCES}

AdAms, J. K. (1957). Laboratory studies of behaviour without awareness. Psychological Bulletin, 54, 383-405.

Balota, D. A. (1983). Automatic semantic activation and episodic memory. Journal of Verbal Learning \& Verbal Behavior, 22, 88-104.

Cheesman, J., \& Merikle, P. M. (1985). Word recognition and consciousness. In D. Besner, T. G. Waller, \& G. E. MacKinnon (Eds.), Reading research: Advances in theory and practice (Vol. 5, pp. 311352). New York: Academic Press.

Cheesman, J., \& Merikle, P. M. (1986). Distinguishing conscious from 
unconscious perceptual processes. Canadian Journal of Psychology, 40, 343-367.

Debner, J. A., \& JACoBy, L. L. (1994). Unconscious perception: Attention, awareness, and control. Journal of Experimental Psychology: Learning, Memory, \& Cognition, 20, 304-317.

De Groot, A. M. B. (1984). Primed lexical decision: Combined effects of the proportion of related prime-target pairs and the stimulus-onset asynchrony of prime and target. Quarterly Journal of Experimental Psychology, 36A, 253-280.

ERIKSEN, C. W. (1960). Discrimination and learning without awareness: A methodological survey and evaluation. Psychology Review, 67, 279300.

Forster, K. I., \& DAVIS, C. (1984). Repetition priming and frequency attenuation in lexical access. Journal of Experimental Psychology: Learning, Memory, \& Cognition, 10, 680-698.

Fowler, C. A., Wolford, G., Slade, R., \& Tassinary, L. (1981). Lexical access with and without awareness. Journal of Experimental Psychology: General, 110, 341-62.

Fuentes, L., \& Tudela, P. (1992). Semantic processing of foveally and parafoveally presented words in a lexical decision task. Quarterly Journal of Experimental Psychology, 45A, 299-322.

Greenwald, A. G., Draine, S. C., \& Abrams, R. L. (1996). Three cognitive markers of unconscious semantic activation. Science, 273, 1699-1702.

Groeger, J. A. (1984). Evidence of unconscious semantic processing from a forced-error situation. British Journal of Psychology, 75, 305314.

Groeger, J. A. (1988). Qualitatively different effects of undetected and unidentified auditory primes. Quarterly Journal of Experimental Psychology, 40A, 323-339.

Holender, D. (1986). Semantic activation without conscious identification in dichotic listening, parafoveal vision, and visual masking: A survey and appraisal. Behavioral \& Brain Sciences, 9, 1-66.

Kunst-Wilson, W. R., \& ZAJONC, R. B. (1980). Affective discrimination of stimuli that cannot be recognized. Science, 207, 557-558.

Logan, G. D. (1985). Executive control of thought and action. Acta Psychologica, 60, 193-210.

Logan, G. D., \& ZBrodoff, N. J. (1982). Constraints on strategy construction in a speeded discrimination task. Journal of Experimental Psychology: Human Perception \& Performance, 8, 502-520.

Logan, G. D., ZBrodoff, N. J., \& Williamson, J. (1984). Strategies in the color-word Stroop task. Bulletin of the Psychonomic Society, 22, 135-138.

MarCel, A. J. (1980). Conscious and preconscious recognition of polysemous words: Locating the selective effect of prior verbal context. In R. S. Nickerson (Ed.), Attention and performance VIII (pp. 435-458). Hillsdale, NJ: Erlbaum.

Marcel, A. J. (1983a). Conscious and unconscious perception: Experiments on visual masking and word recognition. Cognitive Psychology, 15, 197-237.

MarCel, A. J. (1983b). Conscious and unconscious perception: An approach to the relation between phenomenal experience and perceptual processes. Cognitive Psychology, 15, 238-300.

Marcel, A. J. (1988). Phenomenal experience and functionalism. In A. J. Marcel \& E. Bisiach (Eds.), Consciousness in contemporary science (pp. 121-158). Oxford: Oxford University Press, Clarendon Press.

MerikLe, P. M. (1992). Perception without awareness: Critical issues. American Psychologist, 47, 792-795.

Merikle, P. M., \& Cheesman, J. (1987). Current status of research on subliminal perception. In M. Wallendorf \& P. F. Anderson (Eds.), Advantages in consumer research: Vol. XIV (pp. 298-302). Provo, UT: Association for Consumer Research.

Merikle, P. M., \& Daneman, M. (1998). Psychological investigations of unconscious perception. Journal of Consciousness Studies, 5, 5-18.

MerikLe, P. M., \& JoORdens, S. (1997a). Measuring unconscious influences. In J. D. Cohen \& J. W. Schooler (Eds.), Scientific approaches to consciousness (pp. 109-123). Mahwah, NJ: Erlbaum.

Merikle, P. M., \& JoORdens, S. (1997b). Parallels between perception without attention and perception without awareness. Consciousness \& Cognition, 6, 219-236.
Merikle, P. M., Joordens, S., \& Stolz, J. A. (1995). Measuring the relative magnitude of unconscious influences. Consciousness \& Cognition, 4, 422-439.

Merikle, P. M., Smilek, D., \& Eastwood, J. D. (2001). Perception without awareness: Perspectives from cognitive psychology. Cognition, 79, 115-134.

MurPhy, S. T., \& ZaJonc, R. B. (1993). Affect, cognition, and awareness: Affective priming with optimal and suboptimal stimulus exposures. Journal of Personality \& Social Psychology, 64, 723-739.

NeELy, J. H. (1977). Semantic priming and retrieval from lexical memory: Roles of inhibitionless spreading activation and limited-capacity attention. Journal of Experimental Psychology: General, 106, 226254.

NeILl, W. T., \& Kahan, T. A. (1999). Response conflict reverses priming: A replication. Psychonomic Bulletin \& Review, 6, 304-308.

Ortells, J. J., Abad, M. J. F., Noguera, C., \& Lupiáñez, J. (2001). Influence of prime-probe stimulus onset asynchrony and prime precuing manipulations on semantic priming effects with words in a lexical decision task. Journal of Experimental Psychology: Human Perception \& Performance, 27, 75-91.

Posner, M. I., \& SNYDER, C. R. (1975). Facilitation and inhibition in the processing of signals. In P. M. A. Rabbitt \& S. Dornic (Eds.), Attention and performance $V$ (pp. 667-682). New York: Academic Press.

Reingold, E. M., \& Merikle, P. M. (1990). On the inter-relatedness of theory and measurement in the study of unconscious processes. Mind \& Language, 5, 9-28.

SCHNEIDER, W. (1988). Micro Experimental Laboratory: An integrated system for IBM PC compatibles. Behavior Research Methods, Instruments, \& Computers, 20, 206-217.

SEARLE, J. R. (1992). The rediscovery of the mind. Cambridge, MA: MIT Press.

Shenaut, G. K., \& Ober, B. A. (1996). Methodological control for semantic priming in Alzheimer's disease. Psychology \& Aging, 11, $443-$ 448.

Shiffrin, R. M., \& SchneIder, W. (1977). Controlled and automatic human information processing: II. Perceptual learning, automatic attending and a general theory. Psychological Review, 84, 127-190.

SIDIS, B. (1898). The psychology of suggestion. New York: Appleton. Stroop, J. R. (1935). Studies of interference in serial verbal reactions. Journal of Experimental Psychology, 18, 643-662.

\section{NOTES}

1. In a number of previous studies, Merikle and colleagues (e.g., Cheesman \& Merikle, 1985, 1986; Merikle et al., 1995) have consistently found that a prime-mask SOA of $33 \mathrm{msec}$ is below most participants' thresholds for subjective awareness.

2. In discussing the time course of the reversed Stroop effect in the Merikle and Joordens' (1997b) task, we are not suggesting that it necessarily constitutes a pure measure of one and only one type of influencenamely, controlled (strategic) processes. A more reasonable a priori expectation regarding any measure of perception (e.g., priming) is that it often indexes a combination of automatic and controlled (strategic) influences, and whether one or another kind of effect occurs depends on the relative contribution of each type of process. Note that in this sense, the lack of a reliable reversed Stroop in the delayed masking condition at an SOA of $300 \mathrm{msec}$, does not necessarily reflect the absence of strategic influences at that time. Rather, it could be the case that the strategic processes contribute immediately, but such an influence was overridden by an equally large automatic influence. As the automatic influence subsides (i.e., as the SOA interval is lengthened), the strategic influences would then predominate (we thank Bruce Milliken for this suggestion; personal communication, October 25, 2001). In either case, irrespective of whether the reversed Stroop reflects only the contribution of strategic influences or reflects a mixture of strategic and automatic processes, the important point is that obtaining a reliable strategy-dependent priming effect (i.e., reversed Stroop) at an SOA interval of $300 \mathrm{msec}$ seems to be a relatively unusual result in the extant literature.

3. Note that this procedure was equivalent to that used by Merikle and Joordens (1997b), who also presented a practice block followed by six experimental trial blocks with 48 trials per block. 
4. In a previous ANOVA treating trial block as a within-subjects factor, we found no reliable main or interaction effect associated with this variable.

5. Whereas in the immediate masking condition the prime-mask SOA remained constant $(33 \mathrm{msec})$ across the different prime-target SOA groups, this was not the case for the delayed masking condition. Rather, by changing the duration of the blank interval following the 33-msec prime (i.e., 134, 234, 334, and $534 \mathrm{msec}$ ) across the different groups of participants in the delayed masking condition, we varied not only the prime-target SOA (i.e., 300, 400, 500, and $700 \mathrm{msec}$ ) but also the prime-mask SOA in each group (i.e., 167, 267, 367, and $567 \mathrm{msec}$, respectively). Note that an alternative way to vary the prime-target SOA with a delayed mask would have been to change only the duration of the mask (i.e., 133, 233, 333, and $533 \mathrm{msec}$ ) while keeping constant $(134 \mathrm{msec})$ the blank interval following the $33-\mathrm{msec}$ prime. Note, however, a main goal of this and Experiment 3 was to increase the likelihood of obtaining a reliable reversed Stroop effect with a delayed mask. In our view, such a result could more easily be observed by using gradually longer prime-mask SOAs (i.e., gradually longer durations of the blank interval following the prime), rather than always using a constant prime-target SOA of $167 \mathrm{msec}$ (whereas varying the mask durations) for the different prime-target SOA groups. There is, in fact, ample evidence in the literature suggesting that a critical variable for the induction of differential processing (e.g., conscious vs. unconscious) of a masked stimulus is the duration of that stimulus and/or the prime-mask SOA interval, rather than the duration of the mask per se (e.g., Merikle et al., 2001; see also Neill \& Kahan, 1999).

6. Note, in fact, that only half of the participants in the 300-msec SOA group showed a reversal of Stroop interference (i.e., a facilitation effect), whereas the other half showed an opposite interference effect. Likewise, in Experiment 1, fewer than half of the participants in each instruction group (i.e., 7 out of 22 and 9 out of 22, respectively) showed such a strategy-dependent reversed effect.

7. We thank Bruce Milliken for this suggestion (personal communication October 25, 2001).

(Manuscript received July 9, 2001;

revision accepted for publication January 24,2002 .) 